\title{
A construção do pânico moral sobre os ciganos e os imigrantes na imprensa diária portuguesa
}

Sílvia Gomes ${ }^{1}$

Resumo: Neste artigo analisa-se os discursos e representações veiculados pela imprensa diária portuguesa acerca da criminalidade associada a grupos imigrantes ou étnicos. A partir desta análise, pretende-se mostrar como as narrativas que circulam na imprensa transmitem visões sobre a ordem social, que promovem o consenso e o controle social -através da ênfase exagerada sobre o risco de vitimização- e contribuem para a construção do designado "pânico moral". A mediatização da criminalidade produz visões amplamente partilhadas e consensuais, ao mesmo tempo que alimenta, junto do público em geral, visões estereotipadas sobre os "criminosos", podendo associar determinado tipo de criminalidade aos grupos socialmente excluídos e grupos étnicos, tais como ciganos e imigrantes. Esses estereótipos podem converter estes grupos em ameaças potenciais para os interesses e valores vigentes na sociedade, através da produção de cruzadas morais que, pela reação emocional desproporcionada e excessiva que desperta no público, representam os porta-vozes da moralidade e os seus diagnósticos e soluções. Este artigo discute a cobertura da imprensa portuguesa nos casos da criminalidade perpetrada por ciganos e imigrantes como um exemplo paradigmático de um produto de uma indústria cultural. Essas narrativas mediáticas são incitadas por lógicas globais de mercantilização da esfera pública, com base na criminalização da pobreza e no medo de populações urbanas consideradas "problemáticas", cujo objetivo é aumentar a ligação emocional por parte do público e, assim, levar às referidas cruzadas morais.

Palavras-chave: controle social, imigrantes e ciganos, pânico moral, notícia criminal.

Abstract: This paper aims to analyze the discourses and representations conveyed by the Portuguese daily newspapers about criminality related to immigrants and ethnic groups. The intent is to understand how the narratives constructed by the media convey visions of social order to promote consensus and social control through the overemphasis on risk of victimization and the construction of so-called 'moral panic'. The media coverage of crime produces widely shared visions and consensus in different communities, while feeding, in general public, stereotypes

${ }^{1}$ Centro de Investigação em Ciências Sociais; Instituto de Ciências Sociais - Universidade do Minho. E-mail: silvia.gomes@ics.uminho.pt. 
A construção do pânico moral sobre os ciganos e os imigrantes na imprensa diária portuguesa

about the "criminals", and linking the crime to socially excluded groups and ethnic minorities, such as gypsies and immigrants. These stereotypes can convert these groups as potential threats to the interests and values of society, producing a moral crusade that, through the disproportionate and excessive emotional reaction that awakens audiences, represents the spokesmen of morality and their diagnoses and solutions. This paper discusses the media coverage of criminality perpetrated by gypsies and immigrants as paradigmatic example of a product of a cultural industry. These media narratives are nourished by global logics of commodification of the public sphere based on criminalization of poverty and the fear of 'troublesome' urban populations, whose purpose is to raise emotional attachment by the public and lead thus to moral crusades.

Keywords: Immigrants and gypsies, moral panic, crime news, social control.

\section{Introdução}

Há autores que atribuem aos meios de comunicação a responsabilidade pela construção de "dramas públicos" - ou de acordo com a nomenclatura preferida por outros autores "pânico moral" - relacionados com o crime e a justiça, assentes em construções narrativas mediáticas, cujo propósito é o de suscitar adesão emocional por parte do público.

Poderemos distinguir conceptualmente os "dramas públicos" do "pânico moral" na medida em que os primeiros constituem ferramentas heurísticas que contribuem para uma melhor compreensão dos modos como o crime e a justiça são representados, definidos e contestados, incluindo os elementos emocionais. Os "dramas públicos" dizem respeito a fenómenos com efeitos cumulativos e mais prolongados no tempo do que os episódios de "pânico moral" (MACHADO e SANTOS, 2009b).

Ainda assim, o "pânico moral" é um modelo desenvolvido para o estudo das reivindicações contestadas que são feitas por parte de vítimas, grupos de interesse, movimentos sociais, profissionais e políticos, na construção de novas categorias de problema social (COHEN, 2011: xxvii), devido à exploração que tem sido feita do conceito desde que Stanley Cohen o cunhou em "Folk Devils and Moral Panics" (1972).

Neste artigo analisa-se os discursos e representações veiculados pela imprensa diária portuguesa acerca da criminalidade associada a grupos imigrantes ou étnicos - especificamente indivíduos dos Países Africanos de Língua Oficial Portuguesa (PALOP) e do Leste europeu e indivíduos de etnia cigana ${ }^{2}$. A partir desta análise, pretende-se discutir as possíveis implicações dos discursos

${ }^{2} \mathrm{~A}$ escolha destes grupos sociais deveu-se à pertinência analítica que os mesmos tiveram para o desenvolvimento do projeto de Doutoramento da autora. 
mediáticos na formação de estereótipos que associam a prática do crime a determinados grupos sociais, designadamente ciganos, imigrantes dos PALOP e imigrantes do Leste europeu; e, simultaneamente, compreender como essas mesmas narrativas transmitem visões da ordem social de forma a promoverem o consenso e controle social, através da ênfase exagerada dos riscos de vitimização e da construção do pânico moral.

\section{O pânico moral nos estudos sociais do crime}

Um pânico moral designa uma situação em que um indivíduo ou grupo de indivíduos é definido como uma ameaça aos valores e interesses de uma sociedade, sendo a definição e amplificação efetuada, em grande medida, pelos meios de comunicação, e dando lugar a reações da parte dos porta-vozes da moralidade - os moral entrepreneurs (BECKER, 1963) -, que expõem os seus diagnósticos e soluções. Muitas vezes trata-se de uma reação "desproporcionada" e "excessiva" relativamente a algo novo, ou mesmo preexistente, que subitamente se torna o foco de atenção ${ }^{3}$. Portanto, este conceito refere-se às reações públicas e políticas, que são reações sociais consequentes da comunicação social, a grupos ou indivíduos marginalizados que aparentam ser uma espécie de ameaça para os valores e interesses da vida em sociedade (GARLAND, 2008). Os meios de comunicação - liderados pela imprensa - definem, assim, um grupo ou um ato como sendo "desviante" e focam nele, excluindo tudo o resto (JEWKES, 2004, p.64). Este conceito tem as suas raízes na teoria da rotulagem (BECKER, 1963, LEMERT, 1962) e é fundado na assunção de que o ato desviante em si mesmo não é tão importante como a consequente reação a ele (CYR, 2003, p.27). Mais, este promove profecias autorrealizáveis, nas quais os estigmas sociais não limitam apenas a interação social, mas também promovem autoidentificações com grupos e estilos

\footnotetext{
${ }^{3}$ Este é a definição sintetizada por parte de Machado e Santos (2009a), baseando-se no original. A definição de Stanley Cohen é a seguinte: “Uma condição, episódio, pessoa ou grupo de pessoas que emerge para ser definido como uma ameaça aos valores e interesses da sociedade; a sua natureza é apresentada de uma forma estilizada e estereotipada pelos meios de comunicação de massa; as barricadas morais são tripuladas por editores, bispos, políticos e outras pessoas right-thinking; expertes socialmente acreditados pronunciam os seus diagnósticos e soluções; formas de lidar são evoluídas ou (mais frequentemente) recorrem a; a condição depois desaparece, submerge ou deteriora-se e torna-se mais visível. Às vezes o objecto do pânico é uma novidade e outras vezes é algo que já existe há algum tempo, mas que aparece de repente no centro das nossas atenções. Às vezes o pânico passa e é esquecido, excepto no folklore e na memória colectiva; outras vezes eles tem repercussões mais graves e de longa duração e pode produzir mudanças, quer nas políticas sociais e legais ou mesmo na forma como a sociedade se concebe a ela própria" (COHEN, 2011 [1972], p.1)
}

Latitude, Vol. 7, no 2, pp. 187-217, 2013 
A construção do pânico moral sobre os ciganos e os imigrantes na imprensa diária portuguesa

de vida desviantes e até futuros comportamentos desviantes (ALTHEIDE, 2009). Tal como Becker mencionava, os moral entrepreneurs são responsáveis pelas cruzadas morais, que tentam direcionar a atenção do público para um assunto particular e para influenciar o resto da sociedade para acreditar que um sistema de valores específico é superior. Em suma, os moral entrepreneurs criam cruzadas morais, que por sua vez têm o poder de criar novas regras sociais ou legais. As cruzadas morais e o pânico moral são similares, mas eles não são necessariamente a mesma coisa (CYR, 2003, p.28).

Stanley Cohen (2011 [1972]) argumenta que o exagero e distorção da realidade gerada pelos meios de comunicação, pelo público e pela polícia são, em grande parte, inadequados para a real ameaça representada pelos grupos sociais que supostamente ameaçam a ordem social, sendo, assim, o pânico originado pelos moral entrepreneurs, quando estes temem que a ordem social vigente está a ser ameaçada por ações de grupos específicos de pessoas. E, com isto, Cohen defendeu que os meios de comunicação social criam as notícias e as imagens que emprestam a base cognitiva do pânico (HUNT, 1997, p.634).

O conceito de pânico moral foi vastamente estudado desde o trabalho inicial de Cohen ${ }^{4}$ e é isso também que nos dá algum material conceptual e analítico acerca do tema. A tese do pânico moral encerra duas premissas que estimularam um conjunto de trabalhos subsequentes: (i) o facto de o processo de produção noticiosa envolver distorções na forma como a criminalidade é configurada, concorrendo para uma sobrerepresentação do crime quando comparado com os números oficiais (CYR, 2003, p.27, PENEDO, 2003, p.57); (ii) o medo do crime, enquanto experiência subjetiva, não depende exclusivamente da vivência direta do sujeito e da sua experiência real de vitimização (PENEDO, 2003, p.57), mas das fronteiras morais que foram traçadas entre o certo e o errado, o nós e o eles, que faz com que o pânico ocorra quando os "universos morais chocam" (CYR, 2003, p.27).

Hall et al. (1978), no estudo clássico "Policing the Crisis: Mugging, the State, and Law and Order", contrariamente a Cohen (2011 [1972]), proporcionam uma compreensão mais integrada do pânico moral, entendendo-o como o desfrute da ideologia dominante ao consolidar a hegemonia através do aparato discursivo da regulamentação da lei e da ordem (HIER, 2002, p.321). Na perspetiva destes autores, o pânico moral sobre a lei e a ordem são geralmente originados em discursos de membros da polícia e do sistema judiciário, que por sua vez são amplificados pelos meios de comunicação social. Estes não criam as notícias, tanto

${ }^{4}$ Ver Goode e Ben-Yehuda (1994), Hunt (1997), Hier (2002, 2008), Welch, Price, Yankey (2002), Cyr (2003), Doran (2008), Critcher (2008, 2011), Garland (2008), Mawby e Gisby (2009), Altheide (2009), Altheide e Devriese (2007), Rohloff e Wright (2010), Pearce e Charman (2011), David et al (2011), Lumby e Funnell (2011), Young (2011), Lundström (2011), Jenks (2011), Hughes et al (2011). 
quanto reproduzem e sustentam as interpretações dominantes delas, e isso, portanto, pode dizer-se que funciona, conscientemente ou não, como um instrumento de controle do Estado (HUNT, 1997, p.634).

Mais tarde, Goode e Ben-Yehuda (1994) desenvolveram a categorização dos principais grupos de atores sociais que reagem ao comportamento e através dos quais o pânico moral é expressado: os meios de comunicação social, o público, a aplicação da lei, os políticos e a legislação e os grupos de ação (CYR, 2003, p.29). As classes governantes, deliberada e conscientemente, criam pânico moral sobre uma questão - que não reconhecem ser terrivelmente prejudicial para a sociedade como um todo -, por forma de desviar a atenção de problemas mais sérios. Os pânicos morais são assim diversões para quem está no poder que preferem que a "comunidade social e moral" não examinem muito de perto, com medo que descubram o que é realmente importante (HUNT, 1997, p.635).

Estes autores, respondendo à questão "Como sabemos se o pânico moral existe numa determinada sociedade?" (GOODE e BEM-YEHUDA, 1994, p.33), estabeleceram cinco indicadores ${ }^{5}$ para desenvolver uma compreensão crítica deste fenómeno: (i) preocupação (concern) acerca do comportamento dos outros e as possíveis consequências que acreditam que as suas condutas possam ter na sociedade; (ii) consenso (consensus) da existência de uma crença generalizada que o problema é real, que é uma ameaça para a sociedade e que algo deve ser feito; (iii) hostilidade (hostility) relativamente a um grupo ou categoria de pessoas, que são difamadas como párias sociais; (iv) desproporcionalidade (disproportionality), pois o perigo propagado é maior do que o dano potencial; e (v) volatilidade (volatility), uma vez que o pânico moral irrompe de repente e depois desvanece.

Posto isto, percebemos que, tal como qualquer outro acontecimento noticiável (newsworthy), os meios de comunicação constroem pânicos morais, usando para isso o seu critério de valor-notícia. O exagero e a distorção são, portanto, elementos-chave que se encontram no limiar necessário para transformar uma potencial notícia em uma história real (JEWKES, 2004, p.68).

O conceito de pânico moral pode ser usado simultaneamente como modelo processual e instrumento heurístico (PINA, 2009, p.121) e oferece resultados visíveis na análise das notícias criminais, sendo estes exemplos paradigmáticos da existência de pânico moral nas sociedades atuais. Como argumenta Pina (2009), o medo do crime suscitado pela desmesurada presença nos meios de comunicação de casos criminais, em especial crimes violentos, e a indignação que esse fenómeno gere na opinião pública, têm sido classificados como um caso típico de "pânico moral", sobretudo quando o medo se concentra em determinados grupos sociais (imigrantes, ciganos, jovens dos subúrbios, toxicodependentes...) ou em

${ }^{5}$ Vários autores usaram estes indicadores nos seus estudos, entre eles: Welch, Price e Yankey (2002), Mawby e Gisby (2009), Rohloff e Wright (2010) e Garland (2008).

Latitude, Vol. 7, no 2, pp. 187-217, 2013 
A construção do pânico moral sobre os ciganos e os imigrantes na imprensa diária portuguesa

determinadas tipologias de criminosos (pedófilos, abusadores sexuais, homicidas...) (PINA, 2009, p.121-122).

Glosando, através das diferentes contribuições teóricas podemos afirmar que a mediatização da criminalidade produz visões amplamente partilhadas e consensuais, ao mesmo tempo que alimenta, junto do público em geral, visões estereotipadas sobre os "criminosos", podendo associar determinado tipo de criminalidade aos grupos socialmente excluídos e grupos étnicos, tais como ciganos e imigrantes. Esses estereótipos podem converter estes grupos em ameaças potenciais para os interesses e valores vigentes na sociedade, através da produção de cruzadas morais que, pela reação emocional desproporcionada e excessiva que desperta no público, representam os porta-vozes da moralidade e os seus diagnósticos e soluções.

\section{Método e técnicas de coleta de dados}

Sendo possível medir os efeitos dos meios de comunicação social através de conceitos como o pânico moral, é pertinente estudar se os grupos estrangeiros e étnicos representam ou não nos meios de comunicação social e na opinião pública uma ameaça à ordem social da vida em sociedade. Para tal, analisou-se a imprensa diária online portuguesa, por forma a estudar as narrativas acerca dos indivíduos dos PALOP, Leste europeu e de etnia cigana quando diretamente relacionados com práticas consideradas criminosas. Os dados recolhidos foram tratados através do método da análise de conteúdo.

As etapas seguidas para a análise do conteúdo foram as sugeridas por Bardin (1995) - pré-análise, exploração do material e tratamento dos resultados, inferência e interpretação - e foram combinados vários tipos de análise de conteúdo, conjugando análise de exploração com análise de verificação, análise quantitativa com análise qualitativa e análise direta com análise indireta. O material recolhido é muito diverso e, portanto, não pretendemos apenas testar ou verificar hipóteses, mas também explorar o que os dados podiam trazer de novo; não quisemos apenas quantificar e analisar de uma forma direta as variáveis assinaladas nas narrativas, mas também tentar perceber o valor das variáveis apresentadas e fazer a interpretação do que se encontra latente nelas.

A investigação teve como objeto de análise os quatro jornais nacionais diários mais vendidos no país: Correio da Manhã, Jornal de Notícias, Diário de Notícias e Público $^{6}$, sendo que os dois primeiros são mais populares ${ }^{7}$ e os dois últimos ditos

\footnotetext{
${ }^{6}$ Segundo a Associação Portuguesa de Controlo de Tiragens (APCT), os diários generalistas portugueses mais vendidos são: 1) Correio da Manhã com venda de 118.532 exemplares por dia, 2) Jornal de Notícias com 91.422 exemplares por dia, 3) Público com uma média de 37.997 exemplares, 4) Diário de Notícias com 34.408 exemplares, 5) 24 horas com 27.692
} 
de "referência"8. Estes jornais representam posições opostas no campo jornalístico, o "comercial" e o "intelectual", sendo que o primeiro privilegia as notícias "sensacionalistas", enquanto o segundo pretende assentar em valores de "objetividade" e imparcialidade (BOURDIEU, 1994). Resultados de pesquisas anteriores no que diz respeito à representação do crime nos media, como é o caso do estudo de Guibentif (2002), apontam para a existência de diferenças no estatuto socioeconómico do público-alvo destes jornais. O Público, jornal de "referência", é direcionado para um público com maiores rendimentos e habilitações acadêmicas superiores, e, por outro lado, o Correio da Manhã, jornal "popular", é direcionado para leitores com rendimentos mais baixos e menos qualificações acadêmicas (GUIBENTIF, 2002). O facto de existirem diferentes classes nos públicos-alvo dos jornais, implicitamente afeta o papel das "emoções" no estilo jornalístico: enquanto a imprensa de referência usa uma linguagem mais cuidada, que se traduz em esforços de objetividade e imparcialidade que servem pressupostos informativos e explicativos; a imprensa popular usa uma linguagem coloquial em que o vocabulário enfatiza o emocional e o implícito (KATZ, 1987, ERICSON et al., 2010, MACHADO e SANTOS, 2009c).

Assim, a escolha dos jornais não foi feita ao acaso e procuramos estudar os jornais ditos populares e de referência, com o intuito de procurar perceber, através da análise da narrativa, da sua linguagem e construção noticiosa, os registos usados por uns e outros jornais e de que forma estes traduzem formas diferentes ou não da construção da realidade criminal no espaço público.

A partir da observação e recolha online de todas as peças noticiosas com referência direta a práticas consideradas criminosas envolvendo indivíduos de Leste europeu, indivíduos dos PALOP e indivíduos ciganos, no espaço temporal de dois anos (de 1 de Janeiro de 2008 a 31 de Dezembro de 2009), foi possível recolher um corpus de 114 peças. A constituição deste corpus com base num período de dois anos proporcionou uma sólida base de informação, capaz de minimizar os

exemplares e, 6) jornal i com 12.167 exemplares, sendo que a venda diária em banca foi de 8.223 exemplares (www.apct.pt).

${ }^{7}$ Imprensa popular ou "tablóide" é aquela que concede relativamente pouca importância à política, economia e sociedade e uma importância relativamente maior a diversões (como o desporto), a escândalos e a entretenimento popular; e, além disso, dá uma atenção particular a aspectos da vida particular, a aspectos da vida pessoal e privada das pessoas, sejam celebridades ou cidadãos comuns, e descura aspectos como os processos políticos, os desenvolvimentos económicos e as mudanças sociais (SPARKS, 2001, CARVALHO, 2007a). ${ }^{8}$ Por imprensa de referência entende-se a imprensa de âmbito nacional que privilegia o tratamento de temas políticos (nacionais e internacionais), sociais, económicos ou culturais e em que os géneros jornalísticos predominantes são os que dão primazia à reflexão (comentários e estudos). Distingue-se pela sobriedade e relativo distanciamento (MESQUITA e REBELO in CARVALHO, 2007).

Latitude, Vol. 7, nº 2, pp. 187-217, 2013 
A construção do pânico moral sobre os ciganos e os imigrantes na imprensa diária portuguesa

efeitos de certas flutuações temáticas provocadas pelo impacto de determinadas ocorrências conjunturais que induzem um tratamento mediático de exceção, como é o caso das eleições políticas. Neste período ocorreram eleições europeias, legislativas e autárquicas em Portugal e, para não enviesar a amostra com temas que decorrem das propagandas políticas, as peças que focavam os temas centrais em análise não foram consideradas. A partir de um quadro temporal alargado como este foi possível extrair, com alguma margem de segurança, algumas invariantes relativamente à expressão do crime na imprensa diária, podendo a partir daí delimitar uma amostragem de notícias criminais para uma análise mais detalhada do seu conteúdo. A maioria das notícias é do Correio da Manhã (49,1\%), seguido do Diário de Notícias $(28,1 \%)$ e Jornal de Notícias $(20,2 \%)$ com números muito próximos e, por fim, do Público com valores muito baixos $(2,6 \%)$.

Para examinar este corpus, dividimos as variáveis em análise em dois grupos: por um lado, as que se referem à forma e, por outro lado, as que dizem respeito ao conteúdo. De um modo sintético, quanto à forma teve-se em consideração aspetos como o tamanho das notícias e se os títulos informacionais - primário e secundário -, a referência ou não aos sujeitos imigrantes ou minorias étnicas em estudo. No que diz respeito especificamente ao tamanho da notícia, uma vez que a recolha foi efetuada online, considerou-se uma breve notícia que tivesse até 1500 caracteres, 1/4 página uma notícia que tivesse entre 1500-2500 caracteres, 1/2 página entre 25003500 caracteres e uma página ou mais a uma notícia que tivesse mais de 3500 caracteres.

Quanto ao conteúdo, escolheram-se variáveis com uma aproximação ao teor da notícia (ALTHEIDE, 1987). Com uma aproximação ao teor da notícia pretende-se compreender melhor como são classificados os estrangeiros ou grupos étnicos na história (delinquente ou vítima), quais os perfis (gênero, idade, profissão, nacionalidade ou etnia), quais os crimes mencionados, como se dá a atuação das instâncias de controle, quais as fontes de informação que dão sustentação à notícia e quais os locais que aparecem referenciados como sendo espaços de criminalidade.

$\mathrm{Na}$ análise de conteúdo, sempre que aplicável, foram considerados os vários estrangeiros/ imigrantes ou grupos étnicos referidos numa mesma peça, até a um máximo de três referências. Daí que as variáveis relativas à situação jurídica, à atividade profissional, à idade, ao sexo e à nacionalidade ou grupo étnico surjam em triplicado. Considerou-se também até três fontes de informação referenciadas e duas fontes de informação citadas.

No tipo de crime, categorizou-se de acordo com a tipificação presente no Código Penal: (i) crime contra as pessoas (homicídio, abandono, infanticídio, ofensas corporais, maus-tratos a menores, rixa, ameaça, coação, sequestro, rapto, difamação, injúrias); (ii) crime contra valores e interesses da vida em sociedade (violação, lenocínio, tráfico de pessoas, crimes contra sentimentos religiosos, 
falsificação de documentos, moeda, pesos e medidas, crimes contra a ordem e a tranquilidade pública - motim, associação criminosa -, crimes contra o Estado corrupção, peculato); (iii) crime contra o património (furto, burla); (iv) crime contra o património com uso de violência (roubo, extorsão); (v) crime informático; (vi) crime relacionado com drogas (posse ou tráfico).

Além desta análise quanto à forma e ao conteúdo, pretendeu-se levar a cabo uma análise mais minuciosa da teia narrativa, tentando perceber que características do discurso narrado podem ou não ser potenciadores dos dramas morais viventes na opinião pública, adotando para isso aquilo que Altheide (1987) denomina de análise do conteúdo etnográfica. Esta análise é usada para documentar e compreender o significado da comunicação, assim como para verificar as relações teóricas na narrativa, consistindo num movimento reflexivo entre conceitos, amostragem, recolha de dados, codificação e abertura para a criação de novas variáveis que possam surgir na narrativa. Pretende-se assim ser sistemático na análise, mas não demasiado rígido, permitindo o surgimento de novas variáveis e sentidos através da análise das narrativas (ALTHEIDE, 1987, p.68).

\section{Como os transgressores são enformados pela imprensa}

As notícias criminais da imprensa portuguesa diária foram analisadas de acordo com a sua forma e o seu conteúdo, de modo a transparecer como os estrangeiros dos PALOP e do Leste europeu e os indivíduos de etnia cigana são representados e ganham forma nessas narrativas mediáticas, usando para isso as variáveis expostas.

$\mathrm{Na}$ análise da forma das notícias, constatou-se que há referência à nacionalidade, condição de imigrante ou grupo étnico nos títulos informacionais principais e secundários por parte da maior parte dos jornais era reduzida. Todos os jornais, com a exceção do Público, omitem mais vezes os grupos em estudo dos títulos das peças noticiosas, do que os divulgam: o Correio da Manhã não faz referência aos grupos em 80,36\% das notícias recolhidas, o Jornal de Notícias em $60,87 \%$ e o Diário de Notícias em $53,13 \%$. Nestes dois últimos jornais o peso está relativamente distribuído, mas, ainda assim, é interessante notar que há mais peças noticiosas que não fazem referência dos estrangeiros e grupo étnico cigano nos títulos informacionais do que as que fazem.

Num primeiro momento, seríamos levados a considerar que os grupos estrangeiros e étnico cigano não seriam centrais nas notícias criminais. No entanto, os restantes dados formais das notícias mostram-nos uma história diferente. Ao enumerar a frequência com que a pertença a determinada nacionalidade ou grupo étnico é central na notícia dada, reparamos que, em todos os jornais analisados, as personagens principais da notícia são os grupos em estudo. No total, $92 \%$ das 
A construção do pânico moral sobre os ciganos e os imigrantes na imprensa diária portuguesa

notícias tinham o grupo estrangeiro, imigrante ou étnico cigano como tema principal da notícia criminal escrita e divulgada online.

Para além da frequência com que os grupos estrangeiros e étnicos aparecem como personagens centrais nas narrativas, a estrutura da notícia é igualmente importante, pois esta permite intuir da pertinência que esta tem no contexto de um jornal e para caracterizar a profundidade com que a imprensa trata as temáticas do crime, quando relacionado com imigrantes/ estrangeiros e minorias étnicas. Os valores encontrados sobre o tamanho dedicado às notícias criminais revelam diferenças substanciais entre os jornais, o que vem mostrar-nos que o tratamento dado a estas notícias é, apesar de tudo, diferenciado. No Correio da Manhã, 44,6\% das notícias são breves. Somando estas com as notícias de $1 / 4$ de página, observamos que $66 \%$ das notícias do Correio da Manhã têm até um quarto de página. Podemos afirmar, assim, que este jornal dá preferência, tendo em conta a sua linha editorial, ao relato de notícias curtas. O Jornal de Notícias e o Diário de Notícias encontram-se mais ou menos no mesmo patamar, uma vez que as notícias de $1 / 4$ de página e de $1 / 2$ página são as mais encontradas $(60,9 \%$ e $62,5 \%$, respetivamente). Há, nestes jornais, portanto, uma preocupação em desenvolver mais as notícias que digam respeito à criminalidade dos grupos em estudo. As notícias do Público não são em número significativo mas podemos verificar que das três notícias representadas, duas são de meia página e uma de uma página ou mais. Logo, indica que há uma preferência por parte deste jornal por notícias maiores, quando comparado com os outros jornais. O baixo número de notícias relacionando crimes com grupos étnicos neste jornal não traduz uma menor cobertura jornalística destes fenómenos no corpo do seu jornal. Foi possível observar ao longo da recolha das notícias online que as mesmas histórias eram narradas pelos diferentes jornais, mas o jornal Público, apresentando uma linha

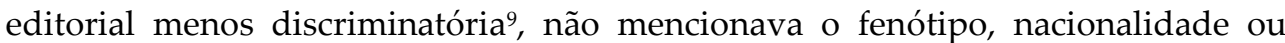
grupo étnico do indivíduo com a mesma frequência que os restantes jornais. Se juntarmos isto ao facto de o jornal Público fazer referência à nacionalidade, condição de imigrante ou grupo étnico cigano na totalidade dos títulos informacionais das notícias que publicou, percebemos que o jornal só faz menção ao grupo em alturas excecionais e que, quando faz, ele é efetivamente central para a notícia.

De acordo com o espaço atribuído em cada um dos jornais em estudo, é possível afirmar que o Correio da Manhã, que é o jornal com mais peças

\footnotetext{
${ }^{9}$ O Código Deontológico do Jornalista português, aprovado em 4 de Maio de 1993, em assembleia geral do Sindicato dos Jornalistas, refere no ponto 8: “O jornalista deve rejeitar o tratamento discriminatório das pessoas em função da cor, raça, credos, nacionalidade ou sexo". Disponível em http://www.rtp.pt/web/organizacao/codigo_deontologico_jornalista.htm.
} 
publicadas nos dois anos, é também o que dá menos espaço para desenvolver o aprofundamento dos acontecimentos relatados, tratando estes de forma superficial. Do lado oposto, o Público, que é o que tem menos peças noticiadas, é o que dá maior espaço para explorar e descrever os acontecimentos criminais. Desta forma, desenvolve e aprofunda mais as narrativas criminais, tal como Carvalho (2007b, p.7) já tinha considerado no seu estudo, onde comparou o jornal Público e Correio da Manhã no tratamento das notícias acerca dos grupos imigrantes e étnicos.

Analisando o conteúdo das notícias criminais, verificou-se que os indivíduos dos PALOP e do Leste europeu e de etnia cigana são referidos nas notícias e aparecem perante o público como sendo os transgressores, os vilões, os culpados nos acontecimentos relatados, tal como é visível noutros estudos (CÁDIMA e FIGUEIREDO, 2003, CARVALHO, 2007a; FERIN-CUNHA et al., 2008a, SANTOS, 2008). Os indivíduos aparecem como transgressores em $66 \%$ das notícias. Contudo, parece haver uma variação entre os jornais analisados. O Correio da Manhã e o Diário de Notícias contribuem para o valor total, apresentando notícias em que é visível um peso significativo destes indivíduos enquanto transgressores (34\% e $22 \%=56 \%$ ). Mas, o Jornal de Notícias e o Público não seguem a mesma tendência, sendo o primeiro igualitário na sua distribuição - das 20,18\% de notícias narradas, $10,53 \%$ apresentam os indivíduos como vítimas e $9,65 \%$ como transgressores - e o segundo possuindo somente casos de vítimas.

No que diz respeito ao perfil dos imigrantes/estrangeiros e grupos étnicos, podemos afirmar que os indivíduos noticiados têm na maior parte dos casos idades entre os 25 e os 34 anos (50\%) ou, se aplicarmos um intervalo maior, entre os 15 e $44(81,4 \%)^{10}$. Todos os jornais têm a mesma tendência em relação à faixa etária dos indivíduos, sendo que o jornal Público não tem dados conclusivos. Relativamente ao sexo, os indivíduos são na sua maioria homens $(84,8 \%)$, sendo que, tal como acontecia na variável anterior, todos os jornais têm a mesma tendência. As notícias recolhidas tinham como condição para serem parte da amostra o facto de fazerem referência a pelo menos um dos grupos em estudo ciganos, indivíduos dos PALOP ou indivíduos de Leste - envolvidos numa situação de crime. A alusão à nacionalidade ou etnia, assim sendo, está presente na totalidade das notícias, mas há grupos que são mais referidos do que outros, esta frequência também varia de jornal para jornal e a forma como os grupos são designados também é variável.

No Correio da Manhã os grupos mais referidos são os cabo-verdianos $(30,4 \%)$, seguidos dos imigrantes de leste $(17,4 \%)$ e dos ciganos $(15,2 \%)$. Já o Jornal de Notícias, o Público e o Diário de Notícias têm a mesma tendência ao nível das nacionalidades/ etnias noticiadas, quando relacionando-as com o crime: Os mais

${ }^{10}$ Estes valores foram recalculados, para um $n$ de 70 em vez de 114 , tendo em conta que 44 $(38,6 \%)$ das notícias não identificam a idade do indivíduo. 
A construção do pânico moral sobre os ciganos e os imigrantes na imprensa diária portuguesa

noticiados são os ciganos, estando em mais de metade das notícias $(55,8 \%, 50 \%$ e $55,2 \%$, respetivamente), e, de seguida, vêm os africanos (11,6\%, $25 \%$ e 10,5\%) e cabo-verdianos $(16,3 \% \text {, } 25 \% \text { e } 7,5 \%)^{11}$. Os cabo-verdianos são os únicos dos mais noticiados, se tivermos em conta todos os jornais em análise, que aparecem com a referência à sua nacionalidade. No conjunto das notícias, agrupando as nacionalidades nos respetivos grupos em estudo, apercebemo-nos de que os indivíduos dos PALOP são os que aparecem mais vezes nas notícias identificados enquanto tal $(39,80 \%)$, seguidos dos indivíduos de etnia cigana $(37,38 \%)$ e dos indivíduos do Leste europeu (22,82\%).

A situação legal e a situação profissional dos indivíduos noticiados não são referidas em $88,6 \%$ e $83,3 \%$ dos casos, respetivamente. Portanto, os jornais, quando se referem aos imigrantes, fornecem informações incompletas. Das poucas vezes em que os imigrantes e/ou etnia cigana são noticiados como vítimas, geralmente aparece mencionada a referência pelo menos à situação profissional do indivíduo, pelo que podemos inferir que os jornais oferecem informações mais completas acerca dos indivíduos vitimados do que acerca dos indivíduos considerados criminosos. Desta forma, o alvo-tipo é mais especificamente e facilmente identificado, deixando o criminoso-tipo enquadrável num âmbito mais lato do fenótipo, do sexo e da geração a que pertence: negro, caucasiano ou cigano, do sexo masculino e jovem.

O crime que mais vezes aparece referenciado nas notícias em análise é o crime contra as pessoas. Todos os jornais seguem a mesma tendência: Correio da Manhã com $52 \%$, o Jornal de Notícias com $74 \%$ e o Diário de Notícias com $50 \%$. Nestas notícias, há uma prevalência do crime de homicídio (49,2\%).

Em termos de tipo de crime noticiado, não há, assim, grandes diferenças entre os jornais generalistas diários portugueses, a não ser quando consideramos o crime relacionado com drogas. O Correio da Manhã, por exemplo, noticia $77 \%$ dos crimes relacionados com drogas. Na totalidade dos casos relacionados com crimes de drogas, 61,5\% (13/8) referem-se ao tráfico de estupefacientes.

Portanto, podemos dizer que nas notícias dominam os crimes violentos contra pessoas (homicídio, ofensas corporais e ameaças) e os crimes que envolvam drogas (posse ou tráfico de drogas ou, até, furtos e roubos que surgem na sequência da condição de traficante ou consumidor de estupefacientes). Estes dados vão ao encontro do que alguns autores defendem quando sustentam que o crime violento se tem tornado cada vez mais num tópico bastante apetecível para a cobertura mediática (SURETTE, 1998, PEELO, 2006, WIESKAMP, 2007). Com efeito, quando comparamos a tendência noticiosa dos jornais nacionais no que diz

\footnotetext{
${ }^{11}$ As designações utilizadas na tabela foram as referidas nas notícias em análise. Entende-se, assim, por que aparece a designação "africanos" e "imigrantes de leste" e, ao mesmo tempo, vários países pertencentes a esses grupos, na mesma tabela.
} 
respeito ao crime com as estatísticas oficiais do crime, vemos que há uma diferença significativa. O crime que é de longe o mais registado pelas entidades policiais é o crime contra o património ${ }^{12 .}$ Comparando com os registos do crime contra as pessoas, vemos que este apresenta um valor francamente abaixo, com menos de metade dos registos em relação ao crime contra o património. Assim sendo, podemos afirmar que o crime noticiado pelos jornais - o crime contra as pessoas é escolhido, não por ser o que mais acontece no país, mas por ser o mais incomum ou mais extraordinário, tornando o crime violento, particularmente o homicídio, mais noticiável (SURETTE, 1998).

Se cruzarmos o tipo de crime noticiado com os grupos em análise, reparamos que, mesmo aparecendo o crime contra as pessoas como sendo o mais comum, verificamos que o tipo de crime que aparece referenciado nas notícias imediatamente a seguir ao crime contra as pessoas difere entre os grupos em análise. Assim, os ciganos são noticiados como cometendo crimes contra o património com o uso de violência (v.g. roubo ou extorsão), os indivíduos dos PALOP são associados a crimes relacionados com drogas (posse ou tráfico) e os indivíduos de Leste conseguem igualar com o crime contra as pessoas, o crime contra valores e interesses da vida em sociedade (v.g. tráfico de pessoas, falsificação de documentos ou moeda, associação criminosa).

No caso particular dos indivíduos ciganos, há estudos nacionais que, trabalhando com as representações sociais, mostram como eles são apelidados de "ladrões" por parte de diversos elementos da sociedade dominante (COSTA, 1995, SILVA e SILVA, 2002, BASTOS, 2007, CORREIA, 2007), com consequências evidentes ao nível das relações de confiança entre os grupos (SILVA e SILVA, 2002).

Os vários locais referidos nas notícias foram agrupados por distrito. No total das notícias em análise, a localidade com maior número de referências é Lisboa (28\%), logo seguida do Porto (24\%). Depois temos Faro (14\%), Setúbal e Aveiro, estes dois últimos com a mesma percentagem (aproximadamente 9\%). Portanto, percebemos que os alegados crimes que são noticiados se dão maioritariamente em zonas urbanas.

As zonas geográficas mais referidas, no total, pelos jornais nacionais, estão relacionadas com as zonas onde se encontram mais estrangeiros, segundo os dados do SEF. Em 2010, há uma concentração da população estrangeira nos distritos de Lisboa, Setúbal e Faro, que totalizam $69,39 \%$ do valor total do país, estando os restantes a norte do país (RIFA, 2010: 19). Este padrão de dispersão dos grupos

12 Dados retirados do site da Direcção Geral da Política de Justiça, http://www.dgpj.mj.pt/sections/estatisticas-da-justica/index/, nos crimes registados pelas autoridades policiais, segundo o ano, por tipo de crime. 
A construção do pânico moral sobre os ciganos e os imigrantes na imprensa diária portuguesa

estrangeiros no território nacional é espelhado também na dispersão dos espaços mencionados nas notícias criminais.

$\mathrm{Na}$ atividade jornalística, as fontes de informação surgem como forma de conferir veracidade e credibilidade aos acontecimentos noticiados (PENEDO, 2007). A principal fonte de informação referenciada pelo conjunto dos jornais em estudo é a polícia (64,63\%), contribuindo em maior medida o Correio da Manhã $(72,46 \%)$ e o Diário de Notícias $(72,22 \%)$ para este valor, embora seja comum a todos os jornais a importância dada a esta fonte de informação. A segunda fonte de informação mais referenciada é os atores do sistema judicial (14,29\%), ficando muito atrás da fonte policial. Para este valor o Público contribuiu em larga medida, com $40 \%$ das suas notícias envolvendo esta fonte. Assim, e na esteira de Hall et al. (1978, p.69), podemos afirmar que as notícias criminais tem origem geralmente em depoimentos de membros da polícia e do tribunal, que depois são amplificados pelos media (HALL et al., 1978, p.69). E, portanto, a imprensa, neste caso, não "cria" as notícias mais do que "reproduz e sustenta" as interpretações dominantes sobre o crime e, assim sendo, pode afirmar-se que a imprensa funciona, intencionalmente ou não, como um instrumento de controle estatal (HALL in HUNT, 1997, p.634).

Embora a polícia e os atores do sistema judicial sejam os mais referenciados nas notícias, as principais fontes de informação citadas nestes jornais - como é visível na tabela 15 - são os cidadãos (53,53\%), quer estes estejam diretamente envolvidos $(20,20 \%)$, quer tenham presenciado os acontecimentos $(33,33 \%)$. Só depois dos discursos dos cidadãos é que vem a voz da polícia, estando presente em $25,25 \%$ das notícias criminais. Assim, o discurso policial surge como forma de legitimar o discurso produzido perante a opinião pública (PENEDO, 2003, p.42) e a voz dos cidadãos aparece como uma forma de imprimir emotividade ao conteúdo noticiado, principalmente quando o cidadão é, ele próprio, testemunha ou vítima da situação descrita (CARVALHO, 2007a). O jornal Público, por outro lado, embora tenha como principais fontes de referência a polícia e os atores do sistema judicial - até porque é através destes meios que muitas vezes as notícias chegam aos jornalistas -, as fontes mais citadas são as escolas ou universidades (50\%), que dão uma explicação mais especializada dos acontecimentos e permitem um aprofundamento das questões explicativas e descritivas dos acontecimentos que são narrados.

A distorção - ao enfatizar apenas determinados crimes, por exemplo - e a desinformação - ao não caracterizar devidamente os sujeitos envolvidos nos acontecimentos noticiados - por parte da imprensa portuguesa, como os estudos acerca do impacto dos media nas perceções do crime parecem confirmar, afetam grandemente, e mais do que as estatísticas oficiais e experiências pessoais de vitimização, as perceções que os cidadãos na sua maioria produzem sobre o crime e os criminosos, desenvolvendo sentimentos de insegurança coletivos, que viabilizam a adoção de políticas criminais cada vez mais severas (PINA, 2009, 
p.120). A imprensa quando menciona os estrangeiros fornece informações incompletas. Os assuntos que são explorados nas notícias criminais não são tanto os detalhes acerca da pessoa que alegadamente cometeu o crime, a não ser que esta seja catalogada num determinado grupo social (como imigrante, negro, cigano, imigrante de leste), nem interessa se ele ou ela está legal ou ilegal, em que condições vive, que trabalho possui (no caso de ter um) ou até o que levou ao alegado crime. Há um "apagamento" do perfil do sujeito, como tem sido sugerido em alguns estudos acerca dos grupos imigrantes e étnicos na imprensa portuguesa (SILVEIRINHA e CRISTO, 2004, p.126, FERIN-CUNHA et al., 2004, p.121). O que é importante é o escrutínio dos detalhes do crime (CARVALHO, 2007a), como foi feito, onde, quem foi a vítima e descrever a história apenas pelo ponto de vista do drama literário. Este discurso dramático que está presente nos discursos mediáticos é o que analisaremos já em seguida.

\section{Da (des)informação ao pânico moral}

A produção de um discurso simplificado é um dos procedimentos clássicos da dramatização, como confirma Babin (1993) a propósito dos media. Algumas características atribuídas ao discurso mediático aproximam-no significativamente de discurso do drama. São disso exemplo os casos como a importância do tempo presente, da simplificação decorrente da necessidade de produzir um discurso claro, do carácter apelativo deste discurso (muitas vezes por via afetiva) e da presença, no caso das notícias, de narrativas caracterizadas por uma concentração da ação em torno de um pequeno núcleo de personagens (SOUSA, 2001).

Para a simplificação do discurso (BABIN, 1993), os jornalistas socorrem-se de pré-conceitos ou rótulos para que os seus leitores, sem precisarem de perder muito tempo nas páginas do jornal, consigam ler a notícia de uma forma imediata e simples (SOUSA, 2001). A rotulagem, de uma forma mais ou menos indicativa, aparece nas notícias analisadas, quando, no perfil dos imigrantes e grupo étnico em análise, mesmo sem recorrer à nacionalidade do sujeito, os jornais referem muitas vezes a sua proveniência através de conceitos vastos como "africanos" ou "imigrantes de leste". Isto faz com que se deixe à imaginação do leitor estes dois grandes rótulos, podendo incluir neles todas as pessoas com os mesmos traços fenotípicos.

Dos mais noticiados, os cabo-verdianos são os únicos que aparecem com a referência à sua nacionalidade. Isto pode ser compreendido através daquilo que Batalha (2009) investigou: em Portugal, a comunicação social, enquanto produtora de identidade, ajudou a criar uma imagem negativa dos descendentes de famílias 
A construção do pânico moral sobre os ciganos e os imigrantes na imprensa diária portuguesa

cabo-verdianas imigrantes ${ }^{13}$. Enquanto os pais eram retratados como "pobres mas honestos", "bons trabalhadores" e "trabalhadores explorados", os filhos são retratados como "vítimas do insucesso escolar" e como "delinquentes juvenis" (BATALHA, 2009). Nas notícias em análise, os cabo-verdianos, geralmente, aparecem como sujeitos de "personalidade violenta", de fisionomia "corpulenta" e sem qualquer hesitação "em apontar armas" às vítimas.

Para além desta adjetivação que induz à estereotipização e rotulação direta de determinado grupo, é de notar que, por vezes, mesmo não tendo a certeza da nacionalidade ou etnicidade dos indivíduos sobre os quais estão a escrever, os jornalistas avançam com formulações que associam os crimes a determinados grupos étnicos, com base em suposições:

"Atado com cinco cordas de nylon e com a cabeça enrolada num pano escuro - supostamente uma saia comprida, típica de uma mulher de etnia cigana. Foi assim que o jovem empresário (...) foi atirado de um precipício (...)" (Correio da Manhã, "Empresário atado e atirado com vida para ribanceira"; 23-12-2008).

Se tivermos em consideração que a maior parte das notícias mostram os estrangeiros/imigrantes e grupo étnico cigano como transgressores, poderemos afirmar que, de uma forma geral, as notícias sugerem que os africanos, os imigrantes de leste e os ciganos são uma ameaça para a sociedade. As narrativas analisadas contribuem, assim sendo, para a visibilidade social de determinados grupos na sociedade portuguesa, como sendo os responsáveis pelo crime ocorrido no país; visibilidade que assenta numa imagem maioritariamente negativa acerca dos mesmos em Portugal. As boas práticas - que aconselham a que não se nomeie a etnia quando se fala de crime - nem sempre são acatadas e tornam, por um lado, invisíveis comunidades que têm necessidade de afirmar a sua existência, bem como a sua diferença, enquanto identidade em construção ou renegociação (FERIN-CUNHA et al., 2008a, p113), e, por outro lado, tornam visível um lado mais

${ }^{13}$ A migração das famílias cabo-verdianas para a "metrópole" iniciou-se nos anos 1960 e continua ainda hoje, embora o ritmo tenha abrandado muito nas décadas de 1990-2000. Muitos eram analfabetos ou apenas tinham a escolaridade básica, frequentemente incompleta (equivalente aos actuais $2 .^{\circ}$ ou $3 .^{\circ}$ anos). No início eram sobretudo homens oriundos de comunidades rurais, por vezes com uma permanência intermédia na cidade local mais próxima, até adquirirem o dinheiro e conhecimento suficientes para fazer o percurso migratório com sucesso. A partir da década de 90, o governo aproveitou dinheiros vindos da UE para a construção de "bairros sociais", onde actualmente vive a maior parte das famílias de imigrantes cabo-verdianos. Os "bairros sociais", à semelhança dos "bairros de lata", constituíram-se como espaços de isolamento social e guetização destes indivíduos (BATALHA, 2009, p.28). 
negativo e pejorativo do crime, não dando voz aos imigrantes e etnias (FERINCUNHA et al., 2008b, p.27).

A oposição criminoso (geralmente violento) e vítima (inocente e indefesa) é clara em qualquer das narrativas dos diferentes jornais em análise. Ao jeito de um drama, utilizam oposições e associações binárias (SOUSA, 2001, 2004) para que o leitor consiga entender quem é que está do lado certo e do lado errado da história narrada, quem é o herói ou a vítima ou quem é o vilão (ERICSON, 1991). Exemplificando, numa notícia do Correio da Manhã ("Sintra: Agressor parado em operação STOP foge com arma na mão"; 10-08-2009), a relação do agressor com a vítima, que neste caso é também polícia, traduz-se nas seguintes descrições:

“Uma simples operação de fiscalização de trânsito (...) acabou por se tornar um verdadeiro pesadelo para um militar da GNR, de 28 anos. O cabo C.A. foi selvaticamente espancado na cabeça e encontra-se em situação clínica grave (...). O agressor roubou-lhe ainda a arma - com que fugiu - depois de a ter apontado ao militar. Depois de o carro ter parado, o homem esmurrou o militar com uma soqueira e deixou-o praticamente inconsciente, aproveitando tal facto para roubar a arma do militar (...) e fugir a pé, antes de os outros guardas o conseguirem intercetar. Ao que o $\mathrm{CM}$ apurou, o agressor, de origem cabo-verdiana, seguia numa viatura com outros quatro homens - de idades compreendidas entre os 25 e 30 anos e da mesma nacionalidade. Deixou caído no chão um documento identificativo que, poderá, todavia, ser falso."

Juntando à oposição existente entre a vítima, "militar da GNR", e o agressor, "cabo-verdiano", e da tensão violenta que nos é sugerida pela adjetivação utilizada ("selvaticamente espancado na cabeça", apontou "arma" e "esmurrou o militar com uma soqueira"), é de realçar que o cenário normal do quotidiano - o policial estava exercendo o seu dever profissional - é transfigurado numa cena de crime. Este ato inesperado salienta, por um lado, o carácter de vilania do crime praticado e, por outro lado, sugere a maior vulnerabilidade a que os cidadãos estão sujeitos, já que nem um profissional de segurança pública está isento de ser vítima num acontecimento criminal. Para além disso, é sugerido na notícia que a identificação do indivíduo poderia ser falsa, associando o delinquente igualmente à falsificação de documentos, mesmo sem qualquer confirmação prévia.

Num artigo do Diário de Notícias ("Condenado a cinco anos por esfaquear polícia"; 12-11-2009) é igualmente realçado o facto de uma ação quotidiana e até um utensílio de cozinha serem transformados num cenário criminoso. Também aqui a vítima foi um polícia, e, para além disso, há um julgamento moral que é reportado pelo próprio jornalista. 
A construção do pânico moral sobre os ciganos e os imigrantes na imprensa diária portuguesa

“O polícia de 37 anos foi esfaqueado, à falsa fé, pelo indivíduo de etnia cigana que residia no acampamento do Parrinho. O golpe do "facão" de cozinha ( 15 x 3,5 centímetros) causou uma ferida grave no pescoço que "por pouco não atingiu uma zona vital". Um corte de 10 centímetros foi suturado com nove pontos. $\mathrm{O}$ agressor, de apelido Monteiro, residia no acampamento cigano (...) O polícia (...) recebeu alta hospitalar na mesma madrugada da tentativa de homicídio, mas ficou algum tempo com apoio psicológico. (...), o agente encontrava-se de sentinela quando resolveu sair das instalações para se abeirar de um homem que por ali rondava com um cão que entrava e saía da receção. O polícia fez o reparo e o suspeito desferiu-lhe um golpe no pescoço com a faca."

De uma forma clara, consegue perceber-se a distinção entre o bem e o mal na construção da notícia. A forma como a vítima - "o polícia de 37 anos" - e o vilão "o agressor" que "residia no acampamento cigano" - são apresentados na narrativa é clara na sua descrição. A vítima era apenas um polícia no exercício das suas funções, "encontrava-se de sentinela", e é esfaqueado "à falsa fé" por um indivíduo de etnia cigana. Todo o discurso é construído no sentido de os leitores aderirem emocionalmente a um dos lados, provocando sentimentos de comiseração ou de repulsa, tratando-se da vítima ou do delinquente, respetivamente. A adjetivação reprobatória e a vilania e violência do agressor fazem-nos pensar no crime como algo individual, fruto do desvio aberrante de uma pessoa malvada (HANEY e MANZOLATI, 1981, BORTNER, 1984, PINA, 2009, HANS e DEE, 2010). Há, assim sendo, uma amplificação emocional (Sousa, 2001, 2004) que não escapa ao leitor, mostrando quais os sentimentos que os leitores devem sentir, enfatizando mais o crime e o criminoso na sua vilania ao longo do texto, do que as possíveis motivações ou explicações para o sucedido e estimulando os sentimentos de vitimização.

As narrativas proporcionam ao público um "sofrimento distante" no qual podem exprimir simpatia pelas vítimas, ao mesmo tempo que alimentam sentimentos de repulsa moral contra os criminosos (BOLTANSKI, 1999, MACHADO e SANTOS, 2009a). Este aspeto é enfatizado não só pelo inusitado acontecimento, mas também pelas consequências que o crime provoca. Por exemplo, o policial da notícia supracitada acaba por ficar vulnerável, necessitando de apoio psicológico depois do sucedido.

Numa outra notícia do Correio da Manhã ("Golpe na cabeça mata exsacristão", 26-04-2009), são enfatizadas exatamente a violência e a brutalidade com que um cabo-verdiano mata um angolano e, ao mesmo tempo, mostrando a vulnerabilidade da vítima, os leitores são convidados a sentir a aflição e a exaltação da vítima: 
"Sebastião tinha ido beber uma bebida ao café frente à igreja da Nossa Senhora da Conceição. Foi ali que, até há pouco tempo, foi sacristão. Apesar de ser reconhecido por todos como 'um homem calmo', o angolano tentou defender-se. O ex-sacristão tirou o casaco para 'começar a lutar com o outro'. 'Foi então que o jovem agarrou num copo grande de cerveja e lhe deu com ele na cabeça', disse ao CM António Virgílio, primo da vítima. Combalido, e a esvair em sangue, o ex-sacristão caiu desamparado no chão. Indiferente ao sofrimento do angolano, o jovem agressor pontapeou-o na cabeça várias vezes. 'O meu primo tem o nariz desfeito e muitos cortes na cara', recordou António Virgílio. No café estava uma funcionária e alguns clientes que tentaram pôr cobro à situação. Impassível, o jovem sacou de uma faca e 'ameaçou toda a gente'. 'Fugiu por um beco'."

A piedade perante o sofrimento da vítima indefesa, acompanhada de indignação justiceira face ao criminoso, remete-nos explicitamente para a exacerbação dos sentimentos associados aos indivíduos intervenientes na história narrada (KARSTEDT, 2010), por um lado, e é característica do discurso "vitimário" da imprensa popular (PINA, 2009, p.132), por outro lado. Como consequência desta sujeição sentimental, os leitores são estimulados na sua capacidade de vitimização. Esta vitimização pode ser real ou potencial. Segundo Banks (2005), quanto mais próximo se está da zona em que determinado acontecimento criminoso acontece, mais facilmente as pessoas sentem um medo real do que lhes poderá acontecer. Portanto, existe uma vitimização real por parte dos leitores e, consequentemente, um medo pertença, de proximidade. Quando esta experiência está ainda longe, a vitimização torna-se um sentimento potencial, que se poderia traduzir na expressão "qualquer dia pode acontecer-lhe a si". Desta forma, estaríamos perante uma vitimização potencial e um medo de referência. Como indicou Lee (2001), o medo do crime não é um "facto social" pré-discursivo, mas uma categoria contingente nascida de um conjunto de disposições e transferências discursivas muito específicas. E, dessa forma, os medos e as vitimizações variam não só de acordo com a espacialização do crime, mas também de acordo com as transferências discursivas que são feitas relativamente a determinados grupos estrangeiros e étnico.

São diversos os discursos ou expressões que potenciam a vitimização e o medo dos leitores face ao crime. De seguida apresentam-se três casos, um do Diário de Notícias, outro do Jornal de Notícias e ainda outro do Correio da Manhã.

"Quatro dezenas de africanos envolveram-se à pancada dentro da carruagem. Agrediram-se a murro e pontapé, à paulada e com armas brancas, incluindo catanas. No mesmo dia, um jovem foi esfaqueado noutro comboio. O pânico instalou-se entre os passageiros do comboio (...). 
A construção do pânico moral sobre os ciganos e os imigrantes na imprensa diária portuguesa

Nenhum passageiro foi atingido, mas a comissão de utentes exige mais presença policial a bordo." (Diário de Notícias, "Pânico no comboio com rixa entre grupos"; 29-08-2009).

O autor da facada terá sido um indivíduo que já se encontrava nas proximidades da esquadra há várias horas - "a rondar, à espera de uma oportunidade" - mas que, quando questionado sobre a sua presença no local, "desviava sempre o assunto". A agressão "deu-se por vingança", adianta a mesma fonte. Em 2008, as buscas que a PSP (...) levou a cabo no acampamento cigano (...) resultaram na apreensão de uma caçadeira que estava na posse de um familiar do alegado atacante." (Jornal de Notícias, "Agente da PSP de S. João da Madeira esfaqueado à porta da esquadra"; 09-03-2009).

“O medo de algumas pessoas que moram no bairro do Vale da Amoreira é evidente. Nesta freguesia de pouco mais de 12 mil habitantes existe uma das maiores concentrações de imigrantes nas imediações de Lisboa, oriundos dos PALOP na década de 70. Desde então, este bairro - que alberga também famílias de etnia cigana - ganhou uma das piores reputações da região, pois é nele que se refugiam vários elementos perigosos ligados ao tráfico de estupefacientes e a assaltos violentos." (Correio da Manhã, "Tiroteio na Amoreira"; 1-09-2009)

As três notícias induzem-nos a pensar na criminalidade como algo que está fora do alcance das pessoas com vidas ditas "normais" e estas são as pessoas que acabam por se sentir potenciais vitimadas (JEWKES, 2004). Na primeira notícia, por exemplo, as pessoas deslocavam-se de transporte para o seu local de trabalho quando se deram os confrontos. Mesmo não tendo ninguém sido agredido, o pânico e a impotência perante o cenário de violência leva a que sejam reclamadas medidas - "exige mais presença policial a bordo". No entanto, várias são as notícias que nos descrevem situações em que são os próprios polícias vítimas da vilania dos agressores. Na segunda notícia, é nos sugerida uma premeditação e profissionalização do crime - "a rondar, à espera de uma oportunidade", "vingança" - contra um policial. Portanto, se o sentimento de insegurança leva à exigência de um maior controle policial, este sentimento não é reconfortado com a existência de notícias como estas. Portanto, lança-se o pânico e os sentimentos de imprevisibilidade e impotência face a uma violência exageradamente retratada pela imprensa portuguesa. Na terceira notícia transcrita, é de salientar a criminalização que é associada aos espaços urbanos, nomeadamente aos bairros sociais. Com efeito, e tal como nos explica Cunha (2010), as áreas residenciais emergem como condições importantes para a relevância da raça ou etnia. Mais que não seja porque essas áreas são mais vezes interpeladas por atuações policiais do 
que outras áreas (CUNHA, 2001, p.112) e, assim sendo, tornam-se mais vulneráveis à exposição mediática.

A associação de indivíduos dos PALOP e de ciganos a bairros problemáticos das áreas metropolitanas de Lisboa ou do Porto é recorrente. Os criminosos residentes nestes espaços, e não só, são encarados como se não fizessem parte do mundo no qual se aplicam regras, valores e considerações de justiça - por residirem nestas áreas urbanas que necessitam, amiúde, de intervenção policial - $\mathrm{e}$ são, geralmente, associados às classes menos favorecidas (MACHADO e SANTOS, 2009a) e ao facto de serem os principais responsáveis pela existência de violência nas ruas (RAMOS e NOVO, 2003, HAYWARD e YAR, 2006).

Para ajudar à provocação dos sentimentos e possível vitimização, as notícias enfatizam nos seus discursos a tragédia, o caos e a subversão, através do uso de determinadas palavras ou expressões que chocam e que mostram o acontecimento como um drama literário. Algumas expressões dão a ênfase à violência "temperamento violento", "espiral de violência", "pesadelo para militar", "ficou um rasto de sangue deixado pelos dois feridos", "invasão armada de um gang de leste", "marcas de balas estão na parede", "apreendido arsenal de armas ilegais", "vítima atacada por um desconhecido", "golpe de facão", "polícias apedrejados", "assaltos com recurso a grande violência", "a faca ficou espetada no pescoço e o cabo, com cerca de um palmo de comprimento, estava à vista" - e outras mostram a consequência dessa mesma violência: "sentimento de insegurança permanente" e "intranquilidade nas pessoas". As notícias do crime acabam por ser histórias de violência ou até mesmo de extrema violência, mostrando como esta é demolidora para a manutenção da lei e da ordem numa sociedade (WEBSTER, 2001).

Os jornais desenvolvem o papel da vítima nos crimes, ao convidar-nos para testemunhar e tomar partido do lado daqueles mais intimamente afetados; o leitor é convidado a focar-se no lado do ofendido contra o ofensor e é encorajado a sentirse magoado com o sucedido; este convite é incorporado a um nível micro nas técnicas de noticiar o crime (PEELO, 2006, p.168). Ao mostrar-nos de que lado é que devemos posicionar-nos em relação à história narrada, uma consequência da narrativa é o próprio exercício de controle e de consenso social, ou seja, a aceitação dos padrões morais vigentes. Através deste posicionamento e do consequente medo do crime, as narrativas promovem uma ideia de desordem e a crença de que as coisas estão fora do controle (ALTHEIDE, 2009), como é visível na notícia do Diário de Notícias, "Pânico no comboio com rixa entre grupos".

O exercício do controle e do consenso sociais através das notícias, por sua vez, podem acabar por formar aquilo a que muitos autores designam de pânico moral. $\mathrm{Ou}$, mais do que isso, pode tornar-se num processo mais lento, cumulativo ao longo de um período de tempo maior do que é o caso de pânico moral (PEELO, 2006, p.169). Todas estas informações manifestas e latentes, que a narrativa jornalística nos proporciona, acabam por produzir uma adesão emocional e moral 
A construção do pânico moral sobre os ciganos e os imigrantes na imprensa diária portuguesa

por parte dos leitores, retratando e defendendo os valores e normas da sociedade dominante.

De forma mais visível, numa notícia do Correio da Manhã, o jornalista deixa a mensagem que se pode traduzir no ditado popular "morder a mão que dá de comer", quando noticia o seguinte:

“Um gang da Europa de Leste (...) protagonizou ontem de madrugada um assalto violento (...). O dono da exploração, um empresário de 58 anos, uma tia idosa, de 86, e uma amiga da família, de 76, foram algemados e agredidos, tendo os ladrões fugido com ouro, prata, duas viaturas e uma caçadeira. (...). Ao que o $\mathrm{CM}$ apurou, muitas das pessoas que pedem emprego a José Santos Lima são imigrantes da Europa de Leste. "Há poucos anos que muita gente do Leste, essencialmente homens e mulheres da Ucrânia, vêm aqui procurar emprego, e trabalham 'à jorna', recebendo ao dia", disse ao CM um morador na zona."

Face aos desvios, este jornal mostra-se mais afirmativo do que os outros na condenação do acontecimento criminoso que relata e tem uma maior tendência para incluir nos seus discursos uma componente normativa, ou seja, alusões mais ou menos expressas ao que se deveria fazer ou não fazer face aos desvios relatados, como já defendia Guibentif (2002, p.60). Mas, além da componente normativa, é de realçar a brutalidade subjacente ao ato criminoso, noticiando as idades das vítimas. Mais uma vez a vulnerabilidade da vítima e brutalidade do crime produz no leitor emoções a que este não consegue escapar.

Um outro aspecto que não podemos deixar de realçar, é que, não raras vezes, aparece quer no discurso do jornalista, quer no discurso dos cidadãos citados, referências racistas e xenófobas. Numa notícia do Correio da Manhã ("O Bruno [Pidá] tinha uma pistola em cada mão" (COM VÍDEO); 22-09-2009), o jornalista cita o discurso de um dos seus entrevistados: "Então ó pretos, agora não fazem nada?, recordou.". O Diário de Notícias ("Perseguiram e mataram jovem no Bairro Alto com facadas"; 09-08-2009) também o faz, na seguinte notícia:

“ "Eu estava na cama a dormir e ouvi gritarem para alguém parar. Fui à janela e vi um grupo de vários pretos a correr atrás de quatro brancos (três raparigas e um rapaz)", contou. "Logo depois, ouvi um grito de aflição, que deve ter sido quando o rapaz levou as facadas e ficou ali estendido no passeio. Os polícias já vinham a pé a perseguir os pretos e conseguiram apanhar três deles. Os outros fugiram", relatou, adiantando que "a faca cheia de sangue ficou no chão". (...).Acrescenta que "o rapaz e as raparigas tinham muito bom aspeto. Todos novinhos, pareciam ser estudantes". 
Quanto aos motivos do crime, uma vizinha diz que, "se calhar, os outros meteram-se com as miúdas, o rapaz não gostou e virou-se a eles..."."

É de constatar que as vítimas são "o rapaz e as raparigas (que) tinham muito bom aspecto...pareciam ser estudantes" e a narrativa é no sentido de estes terem sido inicialmente provocados pelos "pretos". Os "pretos" acabam por não necessitar de serem adjetivados pois aparecem em oposição ao bom aspecto dos estudantes. O criminoso é, por inferência, necessariamente, alguém com pior aspecto do que as suas vítimas.

Aplicando a grelha de análise para a verificação da existência de um caso de pânico moral, conseguimos deduzir que estamos perante uma situação que se aproxima do que é desenvolvido analiticamente pelos autores Goode e BenYehuda (1994). Os cinco indicadores por eles formulados para a descoberta da existência ou não de um pânico moral em determinada sociedade conseguem ser encontrados na análise das notícias criminais analisadas até aqui. Há efetivamente uma "preocupação" (concern) que nos é descrita pela imprensa e pelos próprios cidadãos citados acerca do crime violento praticado por grupos estrangeiros e étnico cigano na sociedade portuguesa, ao ponto de exigirem medidas para combater esse problema, o que nos leva a considerar que há "consenso" (consensus) quando às consequências que esses comportamentos criminais podem ter na sociedade e que são um problema real ao qual tem de haver respostas eficazes. A "hostilidade" (hostility) é percebida pela adjetivação excessiva usada para caracterizar a violência dos atos dos transgressores e a exacerbação dos sentimentos de repulsa face aos mesmos, que é constante em diversas notícias analisadas. De acordo com as estatísticas existentes (SEABRA e SANTOS, 2005) e tendo em consideração que existem mais notícias criminais e, especialmente, notícias criminais relacionadas com grupos estrangeiros e étnicos, podemos afirmar que existe uma desproporcionalidade (disproportionality), já que o perigo percecionado pelos leitores é superior ao dano potencial real. O único elemento que não se verifica na análise é o da volatilidade (volatility), uma vez que ao longo dos dois anos de análise não houve variação de grupos perspetivados como ameaças e existem vários estudos anteriores que nos indicam da preferência pelos mesmos nas notícias portuguesas (VALA, BRITO e LOPES, 1999, CÁDIMA e FIGUEIREDO, 2003, FERIN-CUNHA et al., 2004, 2006, 2008a, 2008b, CARVALHO, 2007a, SANTOS, 2007, 2008, RODRIGUES, 2010).

A teia narrativa varia entre os jornais, apesar de em vários aspetos serem idênticos e são essas similitudes que examinamos aqui. Contudo, não devemos deixar de assinalar que, se recorrêssemos a uma grelha gradual, usando uma escala que vai de sensacionalista a pouco (ou nada) sensacionalista, se tivéssemos em conta a frequência com que aparecem os recursos à dramatização do discurso, a ordem dos jornais analisados seria Correio da Manhã, Diário de Notícias, Jornal de 
A construção do pânico moral sobre os ciganos e os imigrantes na imprensa diária portuguesa

Notícias e Público. Esta ordem corresponde, sensivelmente, à ordem de jornais vendidos em Portugal, sendo que o mais vendido é o mais sensacionalista e o menos vendido é o menos sensacionalista. Mais do que a venda, a questão dos públicos tal como já foi referenciado mais acima é fulcral para entendermos as abordagens escolhidas na redação das peças noticiosas. Podemos, portanto, concluir, de uma forma geral, que o sensacionalismo vende mais e que as pessoas das classes menos formadas e com menos condições econômicas são as que mais procuram este género de notícias.

O Diário de Notícias e o Jornal de Notícias são bastante parecidos no discurso, mas este consegue, no total das notícias, ser um pouco mais contido, recorrendo a termos como "alegadamente" ou "suposto" quando se refere a determinados casos. O Diário de Notícias, embora tenha estas notícias, tem também outras que em muito são parecidas com a abordagem do Correio da Manhã. Poder-se-ia afirmar que o Diário de Notícias apresenta sinais de dualidade, pois não parece haver uma linha editorial bem marcada no que toca a notícias criminais. O Público, das poucas notícias que tem no corpus de análise, denota uma preocupação na linguagem e na abordagem das notícias criminais. Além do uso de expressões como "alegadamente" e "suposto", dá voz a mais intervenientes para além das vozes policiais, frisando preocupações sociais que os outros jornais em análise raras vezes expressam.

A análise das notícias criminais nos jornais populares ou de referência acaba por revelar, neste estudo, que as designações no que diz respeito ao Diário de Notícias e ao Jornal de Notícias não são as mais acertadas. Se o Correio da Manhã é marcadamente popular, ao Jornal de Notícias já não podemos atribuir-lhe essa designação tão facilmente uma vez que se manifesta já uma preocupação, por exemplo, no desenvolvimento das notícias criminais e num certo rigor na linguagem utilizada. O Diário de Notícias é considerado um jornal de referência em Portugal mas presentemente está bastante fragmentado, tendo notícias com características de cada um dos tipos de jornais. O Público, dentre estes jornais, é o único que parece manter algum distanciamento, usando um discurso muito mais factual e informado.

\section{Considerações finais}

A partir da análise das notícias de quatro jornais diários na imprensa nacional portuguesa no período de dois anos, podemos afirmar que as narrativas construídas pela imprensa têm implicações na formação de estereótipos, que associam a prática do crime a determinados grupos sociais, designadamente ciganos, indivíduos dos PALOP e do Leste europeu, em determinadas áreas geográficas do país. De uma forma geral, a perceção pública - que está intimamente relacionada com a difusão mediática de notícias do crime 
Sílvia Gomes

(GUIBENTIF et al., 2002, SACCO, 1995) - é a de que os transgressores normalmente são jovens e do sexo masculino; e que os transgressores de etnia cigana, africanos e imigrantes de Leste se dedicam, respetivamente, à prática de crimes contra o património com o uso de violência (v.g. roubo ou extorsão), crimes relacionados com drogas (posse ou tráfico) e crime contra valores e interesses da vida em sociedade (v.g. tráfico de pessoas, falsificação de documentos ou moeda, associação criminosa).

Os dramas narrados são o que garantem o entretenimento das audiências, através do apelo emocional e moral. Este entretenimento torna-se mais central do que o possível contributo que a imprensa poderia ter na educação e formação cívica das suas audiências (MACHADO e SANTOS, 2009b). Os jornais captam a atenção dos seus leitores - com o recurso à oposição binária entre criminoso e vítima e à adjetivação, por exemplo - e, ao mesmo tempo, provocam situações perversas. Querendo informar, os jornais também entretêm e simultaneamente chocam. Este choque leva, por vezes, a situações de vitimização, de pertença ou de referência e, no limite, a situações de pânico moral.

$\mathrm{O}$ crime acaba por equilibrar em termos de audiência e, igualmente, do ponto de vista lucrativo, pelo que a expressão sobejamente conhecida de que "o crime compensa" poderá ser associada à imprensa portuguesa (COSTA, 2006, p.16), sobretudo à imprensa mais popular. Logo, a "comodificação" é visível nos jornais em estudo, uma vez que a cobertura mediática de casos criminais é formada para consumo e entretenimento e não necessariamente como contributo para a educação e formação cívica das audiências (MACHADO e SANTOS, 2009b).

Ao privilegiar aquilo que é mais extraordinário para as suas audiências, a imprensa dita popular, mais do que a de referência, acaba por adulterar a realidade, criando um pseudo-ambiente (LIPPMANN, 1922). Isto é conseguido através, por exemplo, da sobrerepresentação de determinadas notícias criminais em algumas zonas do país, provocando uma deturpação na perceção da realidade criminal, induzindo, não raras vezes, à sobrerepresentação dos crimes violentos; da alimentação de estereótipos de pessoas e de mitos urbanos sobre o crime, quando procedem à rotulação qualitativamente pejorativa de certos indivíduos ou grupos, com o uso de imagens e linguagem sombrias e sensacionalistas; e da associação de determinadas atividades criminosas aos diferentes grupos em análise, como se cada um dos grupos sociais fosse especializado em determinada prática criminal. A cobertura mediática tende, portanto, a incrementar a "comodificação" do crime às custas de escaladas nas divisões raciais e no medo do crime (SURETTE, 1998, p.78). Desta forma, consegue-se o controle e consenso sociais perante determinados grupos sociais, formando uma opinião pública consensual na designação pejorativa desses grupos, entendendo-os como os inimigos e, em última instância, influenciando as relações sociais entre ambos os grupos.

Latitude, Vol. 7, no 2, pp. 187-217, 2013 
A construção do pânico moral sobre os ciganos e os imigrantes na imprensa diária portuguesa

Portanto, tendo em conta estas últimas perspetivas e todo o corpus analisado, podemos afirmar que as narrativas construídas pela imprensa nacional portuguesa fabricam e reproduzem as lógicas do poder instituído, ao mesmo tempo que podemos assegurar que estas narrativas têm implicações na formação de estereótipos que associam a prática do crime a determinados grupos sociais. Todos estes grupos, de uma forma abstrata, são suscetíveis de serem estereotipados e atormentam o imaginário popular naquilo que pode denominar-se de pânico moral. O pânico moral é explicado por esta indução mediática por parte da imprensa daquilo que alegadamente é a realidade social.

Todos os jornais em análise têm interesse no comportamento criminoso potencial de imigrantes e ciganos na sociedade portuguesa, pois acreditam, pela forma como transparecem nas suas narrativas, que há consequências graves da sua conduta hostil. Os jornais reproduzem a ideia de que estes grupos sociais são um problema real, que constituem uma ameaça para a sociedade e que, portanto, algo deve ser feito sobre isso, inclusive colocar os cidadãos em discurso direto, por exemplo, a exigir mais controle social. Foi possível igualmente observar que há uma desproporcionalidade e um exagero no crime relatado. Na realidade, os jornalistas tendem a enfatizar um tipo de crime que não é a tendência real na sociedade, promovendo sentimentos e vitimização potencial e real.

Tal como no trabalho de Hall et al. (1978), a criminalidade relacionada com os grupos estrangeiros e étnicos parece ter o mesmo enquadramento. Primeiro, a imprensa é dependente das fontes oficiais e, assim sendo, agem como definidores secundários desses definidores primários. Depois, a imprensa converte os discursos dos poderosos ${ }^{14}$ em discurso público, familiar aos seus leitores. De seguida, a imprensa alimenta os seus definidores primários com as suas próprias reações, como se de opinião pública se tratasse. E, por fim, a imprensa sobrevaloriza a violência como forma de justificar a extensão da reação (CRITCHER, 2008, p.1127-1144).

Neste caso em particular poderemos afirmar que os imigrantes dos PALOP, de Leste europeu e grupo étnico cigano são apresentados pela imprensa nacional como grupos que ameaçam os valores e interesses da sociedade portuguesa, a partir do momento em que são noticiados como transgressores, quando não o são como selvagens, provocando reações excessivas. Estas denotam-se a montante e a jusante da produção da notícia. As notícias tendem a enfatizar sentimentos de

${ }^{14}$ Neste caso, o discurso dos poderosos refere-se aos discursos das principais fontes oficiais citadas - polícia e os tribunais. Estes reproduzem, em regra, uma ideologia criminalizadora dos grupos estrangeiros e étnicos, como forma de demonizar um grupo que não é considerado ser merecedor de partilhar o mesmo espaço que os nacionais. Nacionais não ciganos, já que os ciganos não são percepcionados, diversas vezes, enquanto nacionais pelos indivíduos não ciganos portugueses. 
insegurança, vitimização e medo do crime através das reações e opiniões das autoridades e dos cidadãos comuns. Esta tendência pode denotar uma reação exagerada que, por sua vez, tem a capacidade de reproduzir a estigmatização de ciganos e outros grupos étnicos, que é ainda mais visível em períodos de tensão política, econômica e social (WIEVIORKA, 1995, p.15).

\section{Referências bibliográficas}

ALTHEIDE, David. Ethnographic Content Analysis. Qualitative Sociology, vol. 10(1), 65-77, 1987.

ALTHEIDE, David. Moral panic: From sociological concept to public discourse. Crime, Media, Culture, vol. 5, 79-99, 2009.

ALTHEIDE, David, DEVRIESE, Katie. Perps in the News: A Research Note on Stigma. Crime, Media, Culture, vol. 3 (3), 382-389, 2007.

BABIN, Pierre. Linguagem e Cultura dos Media. Venda Nova: Bertrand, 1993.

BANKS, Mark. Spaces of (in)security: Media and fear of crime in a local context.

Crime, Media, Culture, vol. 1(2), 169-187, 2005

BARDIN, Laurence. Análise de Conteúdo. Lisboa: Edições 70, 1995.

BASTOS, José Gabriel Pereira. Que futuro tem Portugal para os portugueses ciganos?. In MONTENEGRO, Mirna (Ed.). Ciganos e Cidadanias. Setúbal: Cadernos ICE, 61-96, 2007

BATALHA, Luís. Cabo-verdianos em Portugal: "Comunidade" e Identidade". In GÓIS, Pedro (Org.). Comunidade(s) Cabo-verdiana(s): As Múltiplas Faces da Imigração Cabo-verdiana. Lisboa: ACIDI, 25-36, 2009.

BECKER, Howard. Outsiders - Studies in the sociology of deviance. New York e London: The Free Press, 1963.

BOLTANSKI, Luc. Distant suffering: Morality, media and politics. Cambridge: Cambridge University Press, 1999.

BORTNER, M. A.. "Media images and public attitudes toward crime and justice". In SURETTE, Ray (Ed.). Justice and the media: Issues and research. Springfield, IL: Charles C. Thomas, 15-30, 1984.

BOURDIEU, Pierre. L'emprise du journalisme. Actes de la Recherche en Sciences Sociales, 101-102, 3-9, 1994.

CÁDIMA, Francisco Rui, FIGUEIREDO, Alexandra. Representações (imagens) dos imigrantes e das minorias étnicas na imprensa. Lisboa: Observatório da Comunicação, 2003.

CARVALHO, Margarida Domingues. A construção da imagem dos imigrantes e das minorias étnicas pela imprensa portuguesa: Uma análise comparativa de dois jornais diários. Tese de Mestrado. Lisboa: Instituto Superior de Ciências do Trabalho e da Empresa, 2007a.

CARVALHO, Margarida Domingues. A construção da imagem dos imigrantes e das minorias étnicas pela imprensa portuguesa: Uma análise comparativa de dois 
A construção do pânico moral sobre os ciganos e os imigrantes na imprensa diária portuguesa

jornais diários. Actas do VI Congresso Português de Sociologia, Lisboa: Associação Portuguesa de Sociologia, 2007b

COHEN, Stanley. Folk devils and Moral Panics: The creation of the Mods and Rockers. London and New York: Routledge, 2011 [1972].

COHEN, Stanley. Whose side were we on? The undeclared politics of moral panic theory. Crime, Media, Culture, vol. 7 (3), 237-243, 2011.

CORREIA, André. «Filhos da estrada e do vento... e da miséria. (...) Porque estas terras são todas deles» - Danos de um relacionamento desigual de longa data. Comunicação apresentada em First International Conference of Youth Urban Researchers. Lisboa: Instituo Superior de Ciências do Trabalho e da Empresa, 2007. Disponível em: http://conferencias.iscte.pt/viewabstract.php?id=216\&cf=3.

COSTA, Artur Rodrigues. Justiça e Comunicação Social. Revista do Ministério Público, vol. 107, 5-26, 2006.

COSTA, Eduardo Maia. Os ciganos em Portugal: breve história de uma exclusão. In CORTESÃO, Luiza, PINTO, Fátima (Ed.). O povo cigano, cidadãos na sombra. Porto: Afrontamento, 13-20, 1995.

CRITCHER, Chas. Moral Panic Analysis: Past, Present and Future. Sociology Compass, vol. 2(4), 1127-1144, 2008.

CUNHA, Manuela Ivone. Entre o Bairro e a Prisão: Tráfico e Trajectos. Tese de Doutoramento. Braga: Universidade do Minho, 2001.

CUNHA, Manuela Ivone, Race, Crime and Criminal Justice in Portugal. In KALUNTA-CRUMPTON, Anita (Ed.). Race, Crime And Criminal Justice: Internacional Perspectives. New York: Palgrave MacMillan, 144-161, 2010.

CYR, Jenna. The Folk Devils Reacts: Gangs and Moral Panic. Criminal Justice Review, vol. 28(1), 25-46, 2003

DAVID, Matthew, ROHLOFF, Amanda, PETLEY, Julian, HUGHES, Jason. The idea of moral panic - ten dimensions of dispute. Crime, Media, Culture, vol. 7(3), 215-228, 2011.

DORAN, Nob. Decoding 'encoding': Moral panics, media practices and Marxist presuppositions. Theoretical Criminology, 12 (2), 191-221, 2008.

ERICSON, Richard. Mass Media, Crime, Law, and Justice. The British Journal of Criminology, vol. 31(3), 219-249, 1991.

ERICSON, Richard et al. Research Approaches (1987). In Chris Greer (Org.). Crime and media: A reader. New York: Routledge, 97-107, 2010.

FERIN-CUNHA, Isabel, SANTOS, Clara Almeida, SILVEIRINHA, Maria João, PEIXINHO, Ana Teresa. Media, Imigração e Minorias Étnicas. Lisboa: AltoComissariado para a Imigração e Minorias Étnicas, 2004.

FERIN-CUNHA, Isabel, SANTOS, Clara Almeida. Media, Imigração e Minorias Étnicas II. Lisboa: Alto-Comissariado para a Imigração e Minorias Étnicas, 2006. 
FERIN-CUNHA, Isabel, SANTOS, Clara Almeida, FILHO, Willy, FORTES, Ilda. Media, Imigração e Minorias Étnicas - 2005-2006. Lisboa: Alto Comissariado para a Imigração e Diálogo Intercultural, 2008a.

FERIN-CUNHA, Isabel, SANTOS, Clara Almeida, FILHO, Willy, FORTES, Ilda. Media, Imigração e Minorias Étnicas - 2007. Lisboa: Alto Comissariado para a Imigração e Diálogo Intercultural, 2008b.

GARLAND, David. On the Concept of Moral Panic. Crime, Media, Culture, vol. 4(1), 9-30, 2008.

GOODE, Eric, BEN-YEHUDA, Nachman. Moral Panics: The Social Construction of Deviance. Oxford: Blackwell, 1994.

GUIBENTIF, Pierre. Comunicação social e representação do crime. Lisboa: Gabinete de Estudos Jurídico-Sociais do Centro de Estudos Judiciários, 2002.

HALL, Stuart, CRITCHER, Chas, JEFFERSON, Tony, CLARKE, John, ROBERTS, Brian. Policing the Crisis: Mugging, the State, and Law and Order. New York: Palgrave Macmillan, 1978.

HANEY, Craig, MANZOLATI, John. Television criminology: Network illusions of criminal justice realities. In ARONSON, E. (Ed.). Readings about the social animal. San Francisco: Freeman, 125-136, 1981.

HANS, Valerie, DEE, Juliet. Cobertura mediática da justice: O impacto nos jurados e no público. In MACHADO, Helena e SANTOS, Filipe (Ed.). Justiça, ambientes mediáticos e ordem social. V.N. Famalicão: Húmus, 36-56, 2010.

HAYWARD, Keith; YAR, Majid. The "chav" phenomenon: Consumption, media and the construction of a new underclass. Crime, Media, Culture, vol. 2(1), 9-28, 2006.

HIER, Sean. Conceptualizing Moral Panic through a Moral Economy of Harm.

Critical Sociology, vol. 28, pp. 311-334, 2002.

HIER, Sean. Thinking beyond moral panic: Risk, responsibility, and the politics of moralization. Theoretical Criminology, vol. 12 (2), 173-190, 2008.

HUGHES, Jason, ROHLOFF, Amanda, DAVID, Matthew, PETLEY, Julian. The context of an emergent and enduring concept. Crime, Media, Culture, vol. 7 (3), 211214, 2011.

HUNT, Arnold. Moral Panic and Moral Language in the Media. The British Journal of Sociology, vol. 48(4), 629-648, 1997.

JENKS, Chris. The context of an emergent and enduring concept. Crime, Media, Culture, vol. 7 (3), 229-236, 2011.

JEWKES, Yvonne. Crime \& Media. London: Sage Publications, 2004.

KARSTEDT, Susanne. Emoções e direito penal. In MACHADO, Helena e SANTOS, Filipe (Ed.). Justiça, ambientes mediáticos e ordem social. V.N. Famalicão: Edições Húmus, 17-38, 2010.

KATZ, Jack, What makes crime "news"?. Media, Culture \& Society, vol. 9, 47-75, 1987. 
A construção do pânico moral sobre os ciganos e os imigrantes na imprensa diária portuguesa

LEE, Murray, The Genesis of 'fear of crime'. Theoretical Criminology, vol. 5 (4), 467485, 2001.

LEMERT, Edwin. Paranoia and the Dynamics of Exclusion. Sociometry, vol. 25, 225, 1962.

LIPPMANN, Walter. Public opinion. New York: The Free Press, 1922.

LUMBY, Catharine, FUNNELL, Nina. Between heat and light: The opportunity in moral panics. Crime, Media, Culture, vol. 7 (3), 277-291, 2011.

LUNDSTRÖM, Ragnar. Between the exceptional and the ordinary: A model for the comparative analysis of moral panics and moral regulation. Crime, Media, Culture, vol. 7 (3), 313-332, 2011.

MACHADO, Helena, SANTOS, Filipe. Dramatização da justiça e mediatização da criminalidade: Que rumos para o exercício da cidadania?. Configurações, vol. 5/6, 55-74, 2009a.

MACHADO, Helena, SANTOS, Filipe. A moral da justiça e a moral dos media: Julgamentos mediáticos e dramas públicos. Oficina do CES, n. 333, 1-18, 2009b.

MACHADO, Helena, SANTOS, Filipe. The disappearance of Madeleine McCann: Public drama and trial by media in the Portuguese press. Crime, Media, Culture, vol. 5(2), 146-167, 2009c.

MAWBY, Rob, GISBY, William. Crime, Media and Moral Panic in an Expanding European Union. The Howard Journal, vol. 48(1), 37-51, 2009.

PEARCE, Julia, CHARMAN, Elizabeth. A social psychological approach to understanding moral panic. Crime, Media Culture, vol. 7(3), 293-311, 2011.

PEELO, Moira. Framing homicide narratives in newspapers: Mediated witness and the construction of virtual victimhood. Crime, Media, Culture, vol. 2(2), 159-175, 2006.

PENEDO, Cristina Carmona. O Crime nos media: o que nos dizem as notícias quando nos falam de crime. Lisboa: Livros Horizonte, 2007.

PINA, Sara. Media e leis penais. Coimbra: Edições Almedina, 2009.

RAMOS, Fabiana, NOVO, Helerina, Mídia, violência e alteridade: Um estudo de caso. Estudos de Psicologia, vol. 8(3), 491-497, 2008.

RODRIGUES, Pedro. Criminalidade na Imprensa. Análise do Correio da Manhã, 2000-2007. Sociologia, Problemas e Práticas, vol. 64, 149-172, 2010.

ROHLOFF, Amanda, WRIGHT, Sarah. Moral Panic and Social Theory: Beyond the Heuristic. Current Sociology, vol. 58(3), 403-419, 2010.

SACCO, Vincent. Media Constructions of Crime. The Annals of the American Academy of Political and Social Science, vol. 539, 141-154, 1995.

SANTOS, Clara Almeida. Imagens de mulheres imigrantes na imprensa portuguesa Análise do ano 2003. Lisboa: Alto-Comissariado para a Imigração e Diálogo Intercultural, 2007.

SANTOS, Clara Almeida. Imagem da imigração e minorias étnicas nos media.

Livro de Actas - 4º SOPCOM, 967-975, 2008. 
SEABRA, Hugo Martinez, SANTOS, Tiago. A criminalidade de estrangeiros em Portugal: um inquérito científico. Lisboa: Alto-Comissariado para a Imigração e Minorias Étnicas, 2005.

SERVIÇO DE ESTRANGEIROS E FRONTEIRAS, Relatório da Imigração, Fronteiras e Asilo 2010. Oeiras: SEF, 2010.

SILVA, Manuel Carlos, SILVA, Susana. Práticas e representações sociais face aos ciganos. O caso de Oleiros, Vila Verde. Antropológicas, vol. 6, 57-86, 2002.

SILVEIRINHA, Maria João, CRISTO, Ana Teresa Peixinho. A construção discursiva dos imigrantes na imprensa. Revista Crítica de Ciências Sociais, vol. 69, 117-137, 2004. SOUSA, Pedro Diniz. Um modelo de análise da dramatização na imprensa escrita. Sociologia, Problemas e Práticas, vol. 35, 79-116, 2001.

SOUSA, Pedro Diniz. Discurso dramático na imprensa: um modelo de análise e o caso do "PREC". Biblioteca Online de Ciências de Comunicação (www.bocc.ubi.pt), 2004.

SPARKS, Richard. The Media, Populism, Public Opinion and Crime. Criminal Justice Matters, vol. 43, 6-7, 2001.

SURETTE, Ray. Media, Crime and Criminal Justice. Belmont: West/ Wadsworth, 1998. VALA, Jorge, BRITO, Rodrigo, LOPES, Diniz. O racismo flagrante e o racismo subtil em Portugal. In VALA, J., BRITO, R., LOPES, D. (Orgs.). Expressões dos racismos em Portugal: perspetivas psicossociológicas. Lisboa: Instituto de Ciências Sociais, 31-60, 1999.

WEBSTER, Colin. Representing Race and Crime. Criminal Justice Matters, 43, 16-17, 2001.

WELCH, Michael, PRICE, Eric, YANKEY, Nana. Moral Panic Over Youth Violence: Wilding and the Manufacture of Menace in the Media. Youth Society, vol. 34(1), 330, 2002.

WIEVIORKA, Michel. Racismo e Modernidade. Venda Nova: Bertrand Editora, 1995. YOUNG, Jock. Moral panics and the transgressive other. Crime, Media, Culture, vol. 7(3), 245-258, 2011. 